\title{
Desempenho e características da carcaça de cordeiros confinados alimentados com grãos de soja
}

\author{
Fumi Shibata Urano( ${ }^{(1)}$, Alexandre Vaz Pires ${ }^{(1)}$, Ivanete Susin ${ }^{(1)}$, Clayton Quirino Mendes ${ }^{(1)}$, \\ Gustavo Henrique Rodrigues ${ }^{(1)}$, Rafael Canonenco de Araujo $^{(1)}$ e Wilson Roberto Soares Mattos ${ }^{(1)}$
}

\begin{abstract}
(1)Escola Superior de Agricultura Luiz de Queiroz, Dep. de Zootecnia, Av. Pádua Dias no 11, Caixa Postal 9, CEP 13418-900 Piracicaba, SP. E-mail: fumyshu@yahoo.com.br, alvpires@esalq.usp.br, ivasusin@esalq.usp.br, cqmendes@esalq.usp.br, ghrodrig@esalq.usp.br, araujo@esalq.usp.br, wrsmatto@esalq.usp.br
\end{abstract}

Resumo - O objetivo deste trabalho foi avaliar a influência de grãos de soja (GS) no desempenho, características e rendimento de cortes de carcaça de cordeiros confinados. Sessenta e quatro cordeiros Santa Inês, com peso vivo inicial de 19,5 $\pm 0,19 \mathrm{~kg}$ e $75 \pm 2$ dias de idade, foram distribuídos em blocos ao acaso de acordo com o peso vivo e a idade no início do experimento. Os GS participaram com 0, 7, 14 e 21\% na matéria seca (MS) das rações isonitrogenadas experimentais. O consumo de MS (1,1, 1,0, 0,9 e 0,9 kg por dia), proteína bruta (199,2, $181,5,179,0$ e 175,2 g por dia) e o ganho de peso vivo (298, 275, 280 e 255 g por dia) diminuíram linearmente, e o consumo de extrato etéreo (43,8, 49,7, 57,2 e 66,0 g por dia) aumentou linearmente com o aumento da participação de GS nas rações. Não houve efeito na conversão alimentar, características e rendimento de cortes da carcaça. A inclusão de GS na ração com alto teor de concentrado proporciona desempenho satisfatório aos cordeiros em confinamento.

Termos para indexação: confinamento, gordura, Santa Inês, ovino.

\section{Performance and carcass characteristics of feedlot lambs fed raw soybean}

\begin{abstract}
The objective of this work was to evaluate the effects of raw soybean on lamb performance, carcass yield and lamb cuts. Raw soybean was added at 0, 7, 14 and 21\% of the diet dry matter (isonitrogenous). Sixtyfour Santa Inês lambs (initial body weight $19.5 \pm 0.19 \mathrm{~kg}$ and $75 \pm 2$ days old) were assigned to a complete randomized block design according to body weight and age at beginning of the trial. Dry matter intake (1.1, 1.0, 0.9 and $0.9 \mathrm{~kg}$ per day), crude protein intake (199.2, 181.5, 179.0 and $175.2 \mathrm{~g}$ per day) and average daily gain (298, 275, 280, 255 g per day) decreased linearly, and ether extract intake (43.8, 49.7, 57.2 and $66.0 \mathrm{~g}$ per day) increased linearly, as levels of raw soybean increased. Feed conversion, carcass yield and lamb cuts were not affected by raw soybean inclusion in the diet. The inclusion of raw soybean in high concentrate diets provides satisfactory feedlot lamb performance.
\end{abstract}

Index terms: feedlot, fat, Santa Inês, sheep.

\section{Introdução}

O rebanho nacional de ovinos é de aproximadamente 15 milhões de cabeças, representando 1,4\% do efetivo mundial, e concentra-se nas regiões Sul (30\%) e Nordeste (58\%) (Brasil, 2006). A produção de carne é uma atividade alternativa, capaz de aumentar a renda nos negócios, não só de ovinocultores, mas de toda a atividade rural.

Apesar de a população brasileira não ter o hábito de consumir carne ovina, observa-se aumento do consumo nos últimos anos. O consumo per capita de carnes no Brasil é da ordem de 65 kg por ano; o consumo de carne de ovinos é de 0,7 kg por ano (Couto, 2001), valor considerado subestimado, já que a maior parte do comércio de carne ovina é informal.

Ao se considerar o elevado custo da terra, principalmente na Região Sudeste, o confinamento é uma estratégia capaz de satisfazer tanto o produtor quanto o consumidor, uma vez que permite reduzir o ciclo de produção e disponibilizar ao mercado carcaças de animais jovens e, conseqüentemente, de melhor qualidade.

As sementes de oleaginosas (grãos de soja, caroço de algodão etc.) são fontes de lipídios, apresentam elevado teor de proteína bruta (PB) e têm custo baixo em determinadas épocas do ano. Segundo o National 
Research Council (1985), grãos de soja (GS) contêm cerca de 94\% de nutrientes digestíveis totais (NDT), valor superior ao encontrado nos grãos de milho, além de elevado teor de PB (42,8\%) e de lipídios (18,8\%). O GS é considerado uma das sementes oleaginosas mais ricas em proteína e energia disponíveis, podendo ser utilizado tanto na alimentação de ruminantes, em sua forma original (crua), quanto na alimentação de monogástricos, na forma processada. Sua utilização pode se tornar economicamente viável aos criadores de ovinos, sobretudo quando são adotados sistemas de confinamento.

No Brasil, o consumo da carne de cordeiro encontrase em desenvolvimento, sendo portanto fundamentais estudos que possam estabelecer o peso ideal de abate, tanto sob o ponto de vista qualitativo quanto econômico (Siqueira et al., 2001).

O objetivo deste trabalho foi avaliar os efeitos da inclusão de grãos de soja em rações com alta proporção de concentrado sobre o desempenho, características e rendimento de cortes da carcaça, bem como a viabilidade econômica das rações utilizadas para cordeiros da raça Santa Inês em confinamento.

\section{Material e Métodos}

O experimento foi realizado no sistema intensivo de produção de ovinos e caprinos (Sipoc), Dep. de Zootecnia da Escola Superior de Agricultura Luiz de Queiroz. Foram utilizados 64 cordeiros da raça Santa Inês, com peso médio inicial de 19,5 $\pm 0,19 \mathrm{~kg}$ e idade média inicial de $75 \pm 2$ dias.

Os animais foram confinados em baias cobertas, e com piso de concreto, cocho e bebedouro. Dois animais foram distribuídos por baia, com oito baias por tratamento.

Todos os animais foram everminados, vacinados contra clostridioses e receberam aplicação de suplemento vitamínico ADE antes do início do experimento. O período experimental teve duração de 56 dias, realizando-se as pesagens no início e final do período experimental, depois de jejum alimentar de 14 horas. As rações foram formuladas para serem isonitrogenadas (18\% PB), constituídas de 10\% de volumoso (feno de coastcross) e $90 \%$ de concentrado na matéria seca (MS), diferindo quanto ao teor de inclusão de GS, que foram de: 0, 7, 14 e 21\% na MS da ração, constituindo os tratamentos experimentais: GS0, GS7, GS14 e GS21, respectivamente (Tabela 1).
As rações foram fornecidas ad libitum, a cada dois dias, e o fornecimento foi ajustado considerando os valores das sobras, as quais foram quantificadas e amostradas semanalmente, para a determinação do consumo diário de MS (CMS). Foram colhidas amostras da ração oferecida e da sobra (10\%) de cada baia (unidade experimental) e conservadas a $-10^{\circ} \mathrm{C}$. Posteriormente, as amostras foram descongeladas e compostas pelos respectivos tratamentos.

Amostras compostas das rações oferecidas e das sobras foram moídas em moinhos do tipo Wiley, providos de peneira com crivos de $1 \mathrm{~mm}$, e analisadas quanto à matéria seca (MS), matéria mineral (MM), extrato etéreo (EE) e proteína bruta (PB), de acordo com a Association of Official Analytical Chemists (1990). A fibra insolúvel em detergente neutro (FDN) foi determinada, utilizando-se $\alpha$-amilase e sulfito de sódio, conforme recomendações de Van Soest et al. (1991).

Ao final do período experimental, um animal por baia, selecionado aleatoriamente, foi abatido ao atingir o peso vivo de abate (PVA) de aproximadamente $35 \mathrm{~kg}$. $\mathrm{O}$ abate foi realizado depois de jejum de 14 horas de alimento sólido, quando os animais foram pesados para obtenção do PVA. A carcaça limpa foi pesada quente, a fim de determinar o peso da carcaça quente (PCQ), e colocada em câmara fria a $2^{\circ} \mathrm{C}$ por 24 horas. Em seguida, as carcaças foram seccionadas longitudinalmente em duas meias-carcaças e pesadas individualmente, obtendo-se o peso das carcaças frias (PCF). Para a determinação do rendimento de carcaça quente (RCQ), rendimento de carcaça fria (RCF) e quebra por resfriamento (QR), foram utilizadas as equações:

Tabela 1. Proporção dos ingredientes e composição bromatológica das rações experimentais (\%MS).

\begin{tabular}{lrrrr}
\hline Ingredientes & \multicolumn{4}{c}{ Tratamentos $^{(1)}$} \\
\cline { 2 - 5 } & GS0 & GS7 & GS14 & GS21 \\
\hline Feno de coastcross & 10,0 & 10,0 & 10,0 & 10,0 \\
Milho moído & 70,3 & 68,5 & 66,7 & 65,0 \\
Farelo de soja & 16,4 & 11,2 & 6,0 & 0,7 \\
Grão de soja moído & - & 7,0 & 14,0 & 21,0 \\
Cloreto de amônio & 0,5 & 0,5 & 0,5 & 0,5 \\
Calcário & 1,2 & 1,2 & 1,2 & 1,2 \\
Mistura mineral ${ }^{(2)}$ & 1,6 & 1,6 & 1,6 & 1,6 \\
\hline Composição bromatológica & & & & \\
MS & 90,4 & 91,0 & 90,7 & 91,0 \\
MO & 85,3 & 85,7 & 85,5 & 85,8 \\
PB & 18,4 & 18,2 & 18,5 & 18,2 \\
EE & 4,2 & 5,1 & 6,1 & 7,0 \\
\hline
\end{tabular}

(1)Tratamentos: GS0: controle; GS7: 7\% de grãos de soja, GS14: 14\% de grãos de soja, GS21: 21\% de grãos de soja na MS da ração. ${ }^{(2)}$ Composição: Ca 13,4\%; P

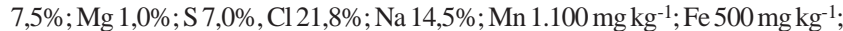

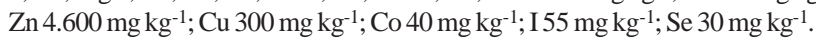


$\mathrm{RCQ}=100(\mathrm{PCQ} / \mathrm{PVA}) ; \mathrm{RCF}=100(\mathrm{PCF} / \mathrm{PVA}) ;$ $\mathrm{QR}=100[(\mathrm{PCQ}-\mathrm{PCF}) / \mathrm{PCQ}]$.

Foram obtidas as medidas de espessura de gordura subcutânea (EG) e área de olho de lombo (AOL) nas meias-carcaças direita e esquerda. A medida da EG foi tomada entre a 12a e 13a costela, na parte posterior da meia-carcaça, com o uso de paquímetro graduado em milímetros. A AOL foi desenhada em papel vegetal, delimitando o contorno do músculo exposto Longissimus dorsi e, posteriormente, mensurada por meio de planímetro graduado em $\mathrm{cm}^{2}$. A meia-carcaça direita foi subdividida nos cortes comerciais: pescoço, costilhar, paleta e pernil, segundo Osório et al. (1998). O costilhar foi subdividido nos cortes comerciais: lombo, costela e matambre. Todos os cortes foram devidamente pesados e identificados.

No final do experimento, foi analisado o custo das rações utilizadas. Calcularam-se os custos da ração, do quilograma da carne produzida e do animal no período de confinamento até atingir o peso de abate de $35 \mathrm{~kg}$.

O delineamento experimental foi o de blocos ao acaso, com oito blocos e quatro tratamentos. Os blocos foram arranjados de acordo com o PV e idade dos animais. A análise estatística foi realizada por meio do GLM do SAS Institute (1996), sendo aplicados testes para polinômios ortogonais, considerando o nível de significância de 5\%.

\section{Resultados e Discussão}

O consumo médio diário de matéria seca (CMS) foi de 1,0 kg por dia, e diminuiu linearmente com o aumento do teor de GS na ração (Tabela 2). Resultados semelhantes foram observados em cabritos alimentados com teores crescentes $(0,8,16$ e $24 \%)$ de caroço de algodão (Luginbuhl et al., 2000) e em cordeiros da raça Awassi alimentados com teores crescentes (0, 2,5 e 5\%) de gordura protegida (Haddad \& Younis, 2004). Provavelmente a redução linear no CMS em quilograma por dia ocorreu em virtude de controle quimiostático (Andrae et al., 2001), no qual o CMS tenha sido ajustado para manter constante o consumo de energia, uma vez que houve aumento da densidade calórica proporcionado pelo elevado teor de gordura na ração.

$\mathrm{O}$ CMS em porcentagem de PV e em grama por quilograma de $\mathrm{PV}^{0,75}$ apresentou efeito quadrático $(\mathrm{p}<0,05)$, de acordo com o aumento do teor de GS, o qual se deve ao menor PV final decorrente do menor ganho de peso vivo (GPV) dos animais do trata- mento GS21, em que a média de CMS (kg por dia) foi semelhante à do tratamento GS14.

O consumo de extrato etéreo (CEE) apresentou valor médio de 54,2 g por dia e 4,7 g por quilograma de $\mathrm{PV}^{0,75}$, e aumentou linearmente com o aumento do teor de GS na ração. Resultados semelhantes foram observados por Luginbuhl et al. (2000) e Haddad \& Younis (2004), que utilizaram teores crescentes de caroço de algodão ( 0 , 8, 16 e 24\%) na ração de cabritos, e de gordura protegida (0, 2,5 e 5\%) na ração de cordeiros Awassi, respectivamente, e observaram aumento no CEE de acordo com a inclusão de gordura na ração.

O consumo médio diário de proteína bruta (CPB) dos cordeiros, neste trabalho, foi de $183,7 \mathrm{~g}$ por dia e 15,7 g por quilograma de $\mathrm{PV}^{0,75}$. O CPB (grama por dia e grama por quilograma de $\mathrm{PV}^{0,75}$ ) diminuiu linearmente $(\mathrm{p}<0,05)$ de acordo com o aumento do teor de GS na ração. Essa diminuição no CPB está relacionada ao CMS (kg por dia) que também apresentou redução linear de acordo com o aumento do teor de GS na ração. O mesmo efeito foi observado por Haddad \& Younis (2004), que avaliaram teores crescentes de gordura protegida na ração de cordeiros e observaram diminuição do CPB decorrente da diminuição no CMS (kg por dia).

O GPV médio neste trabalho foi de $277 \mathrm{~g}$ por animal por dia (Tabela 2), o que foi satisfatório. O GPV observado está de acordo com o National Research Council (1985), que recomenda para GPV de 250 a 300 g por dia, o CPB de 174 a 191 g para ovinos desta categoria.

Tabela 2. Desempenho dos cordeiros no período experimental.

\begin{tabular}{|c|c|c|c|c|c|c|}
\hline \multirow[t]{2}{*}{ Variável $^{(1)}$} & \multicolumn{4}{|c|}{ Tratamento $^{(2)}$} & \multirow[t]{2}{*}{$\mathrm{EPM}^{(3)}$} & \multirow[t]{2}{*}{$\mathrm{p}$} \\
\hline & GS0 & GS7 & GS14 & GS21 & & \\
\hline \multicolumn{7}{|l|}{ CMS } \\
\hline kg por dia ${ }^{(4)}$ & 1,1 & 1,0 & 0,9 & 0,9 & 0,024 & $*$ \\
\hline$\% \mathrm{PV}^{(5)}$ & 3,8 & 3,5 & 3,4 & 3,5 & 0,06 & $*$ \\
\hline g por $\left(\mathrm{kg} \text { de } \mathrm{PV}^{0,75}\right)^{(5)}$ & 86,9 & 80,7 & 78,3 & 80,0 & 1,51 & $*$ \\
\hline \multicolumn{7}{|l|}{ CEE } \\
\hline g por $\operatorname{dia}^{(4)}$ & 43,8 & 49,7 & 57,2 & 66,0 & 1,37 & $*$ \\
\hline $\mathrm{g}$ por $\left(\mathrm{kg} \text { de } \mathrm{PV}^{0,75}\right)^{(4)}$ & 3,7 & 4,2 & 4,9 & 5,8 & 0,09 & $*$ \\
\hline \multicolumn{7}{|l|}{$\mathrm{CPB}$} \\
\hline g por $\mathrm{dia}^{(4)}$ & 199,2 & 181,5 & 179,0 & 175,2 & 4,34 & $*$ \\
\hline $\mathrm{g}\left(\mathrm{kg} \mathrm{de} \mathrm{PV}^{0,75}\right)^{(4)}$ & 16,7 & 15,3 & 15,3 & 15,3 & 0,30 & $*$ \\
\hline PV inicial $(\mathrm{kg})$ & 19,4 & 19,6 & 19,6 & 19,4 & 0,19 & $*$ \\
\hline PV final $(\mathrm{kg})^{(4)}$ & 36,2 & 35,0 & 35,0 & 33,6 & 0,78 & * \\
\hline GPV (g por dia) ${ }^{(4)}$ & 298 & 275 & 280 & 255 & 0,01 & $*$ \\
\hline $\mathrm{CA}$ (kg MS por kg ganho) & 3,6 & 3,5 & 3,4 & 3,7 & 0,01 & ns \\
\hline
\end{tabular}

(1)CMS: consumo de matéria seca; CEE: consumo de extrato etéreo; CPB: consumo de proteína bruta; PV: peso vivo; GPV: ganho de peso vivo; CA: conversão alimentar. ${ }^{(2)}$ GS0: controle; GS7: 7\% de grãos de soja, GS14: 14\% de grãos de soja, GS21: 21\% de grãos de soja na MS da ração. ${ }^{(3)}$ Erro-padrão da média. ${ }^{(4)}$ Efeito linear. ${ }^{(5)}$ Efeito quadrático.

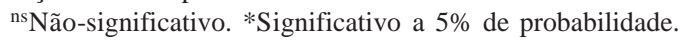


O PV final e o GPV diminuíram linearmente de acordo com o aumento do teor de GS na ração. Resultados semelhantes foram observados por outros autores com a inclusão de teores crescentes de caroço de algodão na ração de cabritos (Luginbuhl et al., 2000) e cordeiros (Moore et al., 1994). No entanto, Rizzi et al. (2002) não verificaram alteração no GPV com o uso de fontes e teores de gordura na ração de cordeiros confinados. Considerando o efeito linear decrescente no GPV com a inclusão do GS, assim como no CMS e CPB, cujos melhores desempenhos foram observados no tratamento controle (GS0), infere-se que o maior GPV seja resultado do maior CPB decorrente do CMS, o que acarretou maior PV final.

Não houve efeito da inclusão de GS na conversão alimentar (CA) (Tabela 2). A média de CA foi de 3,6 kg de MS por quilograma de ganho. A CA verificada foi melhor do que a observada por Siqueira et al. (2001), os quais utilizaram a inclusão de $0,9 \%$ de óleo de soja na ração contendo $60 \%$ de concentrado para cordeiros cruzados Ile de France x Corriedale, e observaram CA de 4,9 kg de MS por quilograma de ganho. FurushoGarcia et al. (2004b) observaram, com o uso de rações com $80 \%$ de concentrado, sem suplementação de gordura, CA de 4,2 kg de MS por quilograma de ganho em cordeiros Santa Inês, ambos observados em cordeiros abatidos aos $36 \mathrm{~kg}$ de PV.

A gordura contém mais energia do que os carboidratos, portanto espera-se aumento na eficiência de utilização da ração consumida, quando a concentração energética da ração é aumentada, desde que o CMS não seja afetado (Gibb et al., 2005). No entanto, dependendo do teor ou fonte de gordura utilizados, o desempenho do animal pode ser comprometido, pois ácidos graxos polinsaturados de cadeia longa livres são potencialmente tóxicos aos microrganismos ruminais, particularmente aos protozoários e bactérias celulolíticas (Palmquist \& Jenkins, 1980), contribuindo para a redução na atividade microbiana e subseqüente digestão (Gibb et al., 2005). Não houve diferença entre os tratamentos para RCQ, RCF e QR, cujas médias observadas foram de 48,9, 47,7 e 2,4\%, respectivamente (Tabela 3).

Furusho-Garcia et al. (2004b) observaram RCF semelhante de 47,6\%, no entanto, 4,3\% de QR em cordeiros Santa Inês abatidos aos 35 kg de PV e 156 dias de idade. Siqueira et al. (2001) observaram valores de QR de $4,3 \%$, RCQ superior (50,6\%) e RCF inferior (41,9\%) em cordeiros cruzados Ile de France x Corriedale, abatidos aos $36 \mathrm{~kg}$ de PV. Osório et al. (2002) observaram valor de 7,2\% de QR, e valores inferiores de RCQ (46,3\%) e RCF (42,9\%) em cordeiros cruzados Border Leicester $\mathrm{X}$
Corriedale e Border Leicester x Ideal, terminados em condições extensivas, abatidos aos 6,5 meses de idade, com $33 \mathrm{~kg}$ de PV.

As médias de AOL e EG nas carcaças dos cordeiros foram de $14,8 \mathrm{~cm}^{2}$ e $1,5 \mathrm{~mm}$, respectivamente, não tendo sido observado diferença entre os tratamentos. Oliveira et al. (2002) observaram AOL e EG superiores, de $18,1 \mathrm{~cm}^{2}$ e $2,4 \mathrm{~mm}$, respectivamente, em cordeiros Santa Inês abatidos aos 210 dias de idade e $45 \mathrm{~kg}$ de PVA, alimentados com ração contendo alto concentrado (80\%). Por sua vez, Siqueira \& Fernandes (2000) avaliaram carcaças de cordeiros Corriedale e cruzados Ile de France x Corriedale confinados e abatidos aos $32 \mathrm{~kg}$, e observaram valores inferiores de AOL, de 8,5 e 9,4 $\mathrm{cm}^{2}$, e EG de 1,4 e 1,5 mm, respectivamente.

A AOL observada foi satisfatória, embora a EG tenha se apresentado baixa, pois, segundo Silva Sobrinho (2001), a espessura de gordura média varia de 2 a $5 \mathrm{~mm}$. Neste trabalho, a EG pode estar relacionada à idade reduzida dos cordeiros abatidos, os quais apresentaram média de 150 dias de idade. Animais jovens tendem a depositar e apresentar menor teor de gordura na carcaça. Deve-se considerar também que, no processo de retirada do couro, é possível que parte dessa gordura tenha sido removida, permanecendo aderida ao couro.

A gordura proveniente da ração tende a promover a sua deposição na carcaça do animal, mas apresenta grande variação, uma vez que esta deposição pode ser influenciada pela fonte de gordura, consumo, estado fisiológico e categoria animal (Grovum, 1986).

Tabela 3. Parâmetros de carcaça e rendimento de cortes dos cordeiros confinados.

\begin{tabular}{lrrrrl}
\hline Variável $^{(1)}$ & \multicolumn{4}{c}{ Tratamento $^{(2)}$} & EPM $^{(3)}$ \\
\cline { 2 - 4 } & GS0 & GS7 & GS14 & GS21 & \\
\hline PVA (kg) & 38,3 & 38,0 & 37,4 & 37,0 & 0,61 \\
RCQ (\%) & 49,6 & 48,8 & 48,3 & 48,8 & 0,64 \\
RCF (\%) & 48,4 & 47,7 & 47,1 & 47,6 & 0,69 \\
QR (\%) & 2,5 & 2,3 & 2,4 & 2,5 & 0,23 \\
AOL (cm $\left.{ }^{2}\right)$ & 15,5 & 14,6 & 14,7 & 14,5 & 0,49 \\
EG (mm) & 1,5 & 1,7 & 1,3 & 1,6 & 0,15 \\
Pescoço & 9,3 & 8,8 & 8,8 & 8,3 & 0,39 \\
Costilhar & 39,1 & 40,6 & 40,6 & 40,3 & 0,80 \\
$\quad$ Lombo & 6,4 & 6,3 & 6,5 & 6,8 & 0,45 \\
Costela & 26,8 & 27,8 & 27,9 & 27,1 & 0,78 \\
Matambre & 6,0 & 6,5 & 6,2 & 6,4 & 0,18 \\
Paleta & 19,5 & 19,4 & 19,0 & 19,5 & 0,38 \\
Pernil & 32,0 & 31,3 & 31,6 & 31,9 & 0,52 \\
\hline
\end{tabular}

(1)PVA: peso vivo de abate; RCQ: rendimento de carcaça quente; RCF: rendimento de carcaça fria; QR: quebra por resfriamento; AOL: área de olho de lombo; EG: espessura de gordura. ${ }^{(2)} \mathrm{GS} 0$ : controle; GS7: 7\% de grãos de soja; GS14: 14\% de grãos de soja; GS21: 21\% de grãos de soja na MS da ração; não houve efeito significativo dos tratamentos. ${ }^{(3)}$ Erro-padrão da média. 
Vários pesquisadores que avaliaram teores e fontes de gordura também não verificaram alterações nas características da carcaça. Da mesma forma, Kandylis et al. (1998) avaliaram teores crescentes (5, 10, 15, 20 e 30\%) de caroço de algodão na ração de cordeiros Karagouniko abatidos aos $30 \mathrm{~kg}$ de PV e 102 dias de idade, e não observaram diferença entre os tratamentos sobre RCQ e RCF, os quais apresentaram médias de 48,2 e 46,7\%, respectivamente. Gibb et al. (2005) utilizaram teores crescentes (0, 2,5 e 5\%) de grãos de cânhamo como fonte de gordura na ração de novilhos, e não observaram diferença na QR, AOL e EG.

Não houve diferença entre os tratamentos quanto ao rendimento dos cortes: pescoço, costilhar, paleta e pernil, os quais apresentaram médias de 8,8, 40,2, 19,4 e 31,7\% do PCF, respectivamente (Tabela 3). O costilhar foi subdivido nos cortes: lombo, costela e matambre, cujas médias foram, respectivamente, de 6,5, 27,4 e 6,3\% do PCF.

Yamamoto et al. (2004) avaliaram a inclusão de fontes de gordura (óleo de soja, canola e linhaça) em rações para cordeiros Santa Inês puros e cruzados Santa Inês x Dorset, abatidos aos $30 \mathrm{~kg}$ com idade aproximada de 150 dias, e também não observaram diferença no rendimento dos cortes: lombo, paleta e pernil de animais alimentados com rações contendo fontes de gordura, em relação à ração controle, observando médias de 9,3, 18,8 e $33,5 \%$, respectivamente, do PCF.

Outros autores observaram resultados variados sem a inclusão de suplementação de gordura, mas com alto teor de concentrado na ração dos cordeiros confinados. Furusho-Garcia et al. (2004a) observaram em cordeiros da raça Santa Inês puros, abatidos aos 35 kg de PV, valores semelhantes de rendimento do pescoço $(8,2 \%)$ e de lombo (3,5\%). Oliveira et al. (2002) observaram valores de paleta, lombo e pernil de 15,4, 8,4 e 28,5\% do PCF, respectivamente, em cordeiros Santa Inês, abatidos aos sete meses de idade, com 43 a $46 \mathrm{~kg}$ de PVA.

Osório et al. (2002) avaliaram carcaças de animais abatidos aos 6,5 meses de idade, cruzados Border Leicester x Corriedale e Border Leicester x Ideal criados extensivamente, e obtiveram valores médios superiores de paleta e pernil: 20,6 e 34,9\% do PCF, respectivamente, mas rendimentos inferiores dos cortes: pescoço e costilhar: 8,5 e 36,0\% do PCF, respectivamente.

Trabalhos utilizando métodos semelhantes aos utilizados neste experimento, em carcaças de ovinos Santa Inês, são escassos, mas, considerando as observações de diversos autores, os valores de rendimento de cortes observados foram satisfatórios (Tabela 4).
Tabela 4. Custo de produção de cordeiros baseado no custo da ração.

\begin{tabular}{lcccccc}
\hline Tratamento $^{(1)}$ & $\mathrm{CA}^{(2)}$ & $\begin{array}{c}\text { Custo da } \\
\mathrm{MS} \\
\left(\mathrm{R} \$ \mathrm{~kg}^{-1}\right)\end{array}$ & $\begin{array}{c}\text { Custo } \\
\text { diário do } \\
\text { animal }(\mathrm{R} \$)\end{array}$ & $\begin{array}{c}\text { Custo da } \\
\text { carne } \\
\left(\mathrm{R} \$ \mathrm{~kg}^{-1}\right)\end{array}$ & $\mathrm{PC}^{(3)}$ & $\begin{array}{c}\text { Custo } \\
\text { total no } \\
\mathrm{PC}(\mathrm{R} \$)\end{array}$ \\
\hline GS0 & 3,6 & 0,34 & 0,36 & 1,2 & 52 & 18,7 \\
GS7 & 3,5 & 0,34 & 0,32 & 1,2 & 56 & 17,9 \\
GS14 & 3,4 & 0,33 & 0,31 & 1,1 & 55 & 17,1 \\
GS21 & 3,7 & 0,33 & 0,31 & 1,3 & 61 & 18,9 \\
\hline
\end{tabular}

${ }^{(1)}$ Tratamentos: GS0: controle; GS7: 7\% de grãos de soja, GS14: 14\% de grãos de soja, GS21: $21 \%$ de grãos de soja na MS da ração. ${ }^{(2)}$ Conversão alimentar. (3)Período de confinamento.

Neste trabalho, o período de confinamento (PC) necessário para cordeiros dos tratamentos GS0 a GS21 atingirem o peso de abate de $35 \mathrm{~kg}$ variou de 52 a 61 dias. Os maiores custos de produção relacionados ao custo da ração foram observados nos tratamentos GS21, o qual apresentou maior PC, e GS0, embora este tenha apresentado menor PC.

Os cordeiros alimentados com GS14 apresentaram menor custo de alimentação por animal no PC, indicando maior viabilidade econômica da ração.

\section{Conclusões}

1. A conversão alimentar, o rendimento de cortes e as características da carcaça não são alterados pela inclusão de grãos de soja na ração para cordeiros em crescimento, embora o consumo diário de matéria seca e o ganho de peso vivo sejam afetados negativamente.

2. A inclusão de grãos de soja em até $14 \%$ na matéria seca da ração é recomendada, considerando-se o seu custo em relação aos demais ingredientes.

\section{Agradecimentos}

À Fapesp, pelo financiamento do projeto.

\section{Referências}

ANDRAE, J.G.; DUCKETT, S.K.; HUNT, C.W.; PRITCHARD, G.T.; OWENS, F.N. Effects of feeding high-oil corn to beef steers on carcass characteristics and meat quality. Journal of Animal Science, v.79, p.582-588, 2001.

ASSOCIATION OF OFFICIAL ANALYTICAL CHEMISTS. Official methods of analysis. $15^{\text {th }}$ ed. Arlington, 1990. v.1, 1117p.

BRASIL. Ministério da Agricultura, Pecuária e Abastecimento. Brasil: rebanho ovino - efetivo por Unidade da Federação. Disponível em: <http://www.agricultura.gov.br>. Acesso em: 4 set. 2006. 
COUTO, F.A. d'A. Apresentação de dados sobre a importância econômica e social das palestras técnicas previstas no programa. In: REUNIÃO TÉCNICA “APOIO À CADEIA PRODUTIVA DA OVINO-CAPRINOCULTURA BRASILEIRA”, 2001, Brasília. Relatório final. Brasília: CNPq, 2001. p.10-15.

FURUSHO-GARCIA, I.F.; PEREZ, J.R.O.; BONAGURIO, S.; ASSIS, R.M.; PEDREIRA, B.C.; SOUZA, X.R. Desempenho de cordeiros Santa Inês puros e cruzas Santa Inês com Texel, Ile de France e Bergamácia. Revista Brasileira de Zootecnia, v.33, p.15911603, 2004b.

FURUSHO-GARCIA, I.F.; PEREZ, J.R.O.; BONAGURIO, S.; LIMA, A.L.; QUINTÃO, F.A. Estudo dos cortes da carcaça de cordeiros Santa Inês puros e cruzas Santa Inês com Texel, Ile de France e Bergamácia. Revista Brasileira de Zootecnia, v.33, p.453462, 2004a.

GIBB, D.J.; SHAH, M.A.; MIR, P.S.; McALLISTER, T.A. Effect of full-fat hemp seed on performance and tissue fatty acids of feedlot cattle. Canadian Journal of Animal Science, v.85, p.223-230, 2005.

GROVUM, W.L. The control of motility of the ruminoreticulum. In: MILLIGAN, L.P.; GROVUM, W.L.; DOBSON, A. (Ed.). Control of digestion and metabolism in ruminants. Englewood Cliffs: Prentice-Hall, 1986. p.18-40.

HADDAD, S.G.; YOUNIS, H.M. The effect of adding ruminally protected fat in fattening diets of nutrient intake, digestibility and growth performance of Awassi lambs. Animal Feed Science Technology, v.113, p.61-69, 2004.

KANDYLIS, K.; NIKOKYRIS, P.N.; DELIGIANNIS, K. Performance of growing-fattening lambs fed whole cotton seed. Journal of the Science Food and Agriculture, v.78, p.281-289, 1998.

LUGINBUHL, J.M.; POORE, M.H.; CONRAD, A.P. Effect of level of whole cottonseed on intake, digestibility, and performance of growing male goats fed hay-based diets. Journal of Animal Science, v.78, p.1677-1683, 2000.

MOORE, J.A.; POORE, M.H.; POND, K.R. Performance of lambs fed varying levels of whole cottonseed. Journal of Animal Science, v.72, p.382, 1994. Supplement 1.

NATIONAL RESEARCH COUNCIL. Nutrient requirements of sheep. $6^{\text {th }}$ ed. Washington: National Academic Press, 1985. 99p.

OLIVEIRA, M.V.M.; PÉREZ, J.R.O.; ALVES, E.L.; MARTINS, A.R.V.; LANA, R.P. Rendimento de carcaça, mensurações e peso de cortes comerciais de cordeiros Santa Inês e Bergamácia alimentados com dejetos de suínos em confinamento. Revista Brasileira de Zootecnia, v.31, p.1451-1458, 2002. Suplemento.

OSÓRIO, J.C.S.; OLIVEIRA, N.M.; OSÓRIO, M.T.M.; JARDIM, R.D.; PIMENTEL, M.A. Produção de carne em cordeiros cruza Border Leicester com ovelhas Corriedale e Ideal. Revista Brasileira de Zootecnia, v.31, p.1469-1480, 2002. Suplemento.

OSÓRIO, J.C.S.; OSÓRIO, M.T.M.; JARDIM, P.O.C.; PIMENTEL, M.A.; POUEY, J.L.O.; LÜDER, W.E.; CORDELLINO, R.A.; OLIVEIRA, N.M.; GULARTE, M.A.; BORBA, M.F.; MOTTA, L.; ESTEVES, R.; MONTEIRO, E.; ZAMBIAZI, R. Métodos para avaliação de carne ovina “in vivo", na carcaça e na carne. Pelotas: Ed. Universitária/UFPEL, 1998. $107 p$.

PALMQUIST, D.L.; JENKINS, T.C. Fat in lactation rations. Journal of Dairy Science, v.63, p.1-14, 1980.

RIZZI, L.; SIMIOLI, M.; SARDI, L.; MONETTI, P.G. Carcass quality, meat chemical and fatty and fatty acid composition of lambs fed diets containing extruded soybeans and sunflower seeds. Animal Feed Science and Technology, v.97, p.103-114, 2002.

SAS INSTITUTE (Cary, Estados Unidos). SAS systems for Windows. Version 6.12. Cary, 1996. 842p.

SILVA SOBRINHO, A.G. Aspectos quantitativos e qualitativos da produção de carne ovina. In: REUNIÃO ANUAL DA SOCIEDADE BRASILEIRA DE ZOOTECNIA, 38., 2001. A produção animal na visão dos brasileiros. Piracicaba: FEALQ, 2001. p.425-453.

SIQUEIRA, E.R.; FERNANDES, S. Efeito do genótipo sobre as medidas objetivas e subjetivas da carcaça de cordeiros terminados em confinamento. Revista Brasileira de Zootecnia, v.29, p.306311, 2000

SIQUEIRA, E.R.; SIMÕES, C.D.; FERNANDES, S. Efeito do sexo e do peso ao abate sobre a produção de carne de cordeiro. I. Velocidade de crescimento, caracteres quantitativos da carcaça, $\mathrm{pH}$ da carne e resultado econômico. Revista Brasileira de Zootecnia, v.30, p.844848, 2001.

VAN SOEST, P.J.; ROBERTSON, J.B.; LEWIS, B.A. Methods for dietary fiber, neutral detergent fiber, and nonstarch polysaccharides in relation to animal nutrition. Journal of Dairy Science, v.74, p.3583-3597, 1991.

YAMAMOTO, S.M.; MACEDO, F.A.F.; MEXIA, A.A.; ZUNDT, M.; SAKAGUTI, E.S.; ROCHA, G.B.L.; REGAÇON, K.C.T.; MACEDO, R.M.G. Rendimentos dos cortes e não-componentes das carcaças de cordeiros terminados com dietas contendo diferentes fontes de óleo vegetal. Ciência Rural, v.34, p.1909-1913, 2004.

Recebido em 12 de dezembro de 2005 e aprovado em 19 de junho de 2006 